\title{
On the Integration of Culture into EFL Teaching
}

\author{
Yongmei Jiang \\ Foreign Language School, Qingdao University of Science and Technology \\ Qingdao 266061, Shandong, China \\ E-mail: yongmeijiang716@126.com
}

\begin{abstract}
After a brief introduction, this paper dwells on cultural differences, and then answered the question "Why should culture be included in English teaching" from three aspects.

Keywords: Culture, Differences, Teaching

\section{Introduction}

Language is among the culture, and in turn it reflects the culture. They are in so complete harmony that the differences of language using unavoidably symbolize the cultural differences, and vice versa. Foreign language learning is comprised of several components, including grammatical competence, communicative competence, language proficiency, as well as a change in attitudes towards one's own or another culture (Claire Kramsch, 1999). Of them, cultural competence has been viewed by many teachers as their goal to incorporate the teaching of culture into the foreign language curriculum. English speaking and writing two tough problems as to those Chinese students in their English learning. Among other things, the different ways of Chinese thinking and expression are the two basic reasons. So, a foreign language teacher should be first a culture teacher, having the ability to experience and analyze both the home and target cultures. Undoubtedly, the lack of English knowledge accounts for one of the phenomena. On the other hand. The overlook of culture instruction makes it unavoidable. It is well-known that culture, language and thought are an organic part, in which the interaction occurs among the three factors. As a result, cultural differences not only in the form, sentences and vocabularies but also in the way of thinking and expression habit, Can be seen obviously from a speech or writing product by a Chinese.
\end{abstract}

\section{Cultural Differences}

\subsection{Problems Caused by cultural differences}

As the information technology develops so rapidly at present, the economic globalization brings about culture fusion as well as culture conflicts. McDonald' s, KFC, Nike an d Coke are among those English words well mirrored in the Chinese language. At the same time, "dim sum", "kowtow and wok" have come to be examples of the Chinese language and culture in America. However as a coin has two sides, the ever-growing interactions among peoples with different cultures and languages also expose foreign language learners to greater risks of committing cultural blunders. Here are some examples:

Example One:

Mary: You look beautiful in that overcoat.

Hong: No, it is old. I don't think it's beautifu1.

In this dialogue, Mary praises Hong's overcoat, but Hong answers in a self-defacing way traditional for most Chinese. But to Mary (an American), it is regarded to be rude to express your gratitude this way. It is a denial to her connoisseurship.

Example Two:

Chinese greet each other cordially "Where are you going?" although they actually don't really want to know where the others are going. A British woman walks to the cinema on campus in China, her student greets her in a traditional Chinese way by saying "Are you going to see the film?" The British woman feels very odd as she thinks that her going there is so obvious and why the student asks such a question. And the greeting of: "Have you eaten?" can be interpreted 
as an infringement of privacy on the part of an English—speaking addressee.

\subsection{What is culture?}

Culture exists everywhere in human society. Even when a baby is born, his thought and behavior are influenced by culture subconsciously. Due to such a nature, it is hard to reach an agreement on a single definition of culture. There is really very little agreement on what people mean by the idea of culture since culture has different shades of meanings in different scientific disciplines and context. The English anthropologist E.B. Tylor first set his definition in his Primitive culture in 1871: "Culture is that complex whole which includes knowledge, beliefs, arts, morals, law, customs, and other capabilities and habits acquired by man as a member of society”(WANG Fu—xiang\&WU Han-ying, 1994, P.79). Daniel Bates and Fred Plog advance another definition with detailed descriptions: Culture is a system of shared beliefs, values, customs, behaviors, and artifacts that the members of a society, to cope with their world and with one another, and that is transmitted from generation to generation through learning. This definition includes not only patterns of behavior but also patterns of thought(shared meanings that the members of a society attach to various phenomena, natural and intellectual, including religion and ideologies), artifacts(tools, pottery, houses, machines, works of art), and the culturally transmitted skills and techniques used to make the artifacts(Quoted from Lamj. Samover\&Richard E. Porter, 1995, P47).

\subsection{A brief survey on Chinese culture and western culture}

The traditional Chinese world view is "oneness between man and nature", which refers to obedience of man to the natural law and the worship of nature. Under the guidance and influence of this idea, we Chinese tend to achieve wholeness, generality, synthesis and believe in intuition. Thus there is little mobility, either socially or geographically. Under the traditional education of Confucianism, Taoism and Buddhism, Chinese respect the old and care the young; they are kind to neighbors; they behave themselves and are modest and prudent. China's education advocates discipline and obeying the law, industry and thrift in managing a house and obedience to one's superiors. China has been an agricultural country for five thousand years. This agrarian nature distributes to the traits and values that characterize the society both in the past and today. Chinese families are cohesive units in which all members work together and live together. Thus forms the collective nature of Chinese values.

Western culture is relatively young. People there respect religious freedom and have a great faith that everyone is born to be equa1. Most of the countries were once greatly immigrant; different values, norms and customs were melted together. Everyone is equal to seek for wealth and liberty. People depend on themselves rather than others. They develop habits of survival based on individualism, and also such thought patterns, beliefs, values and attitudes.

Chinese culture belongs to the oriental culture while the western culture is the occidenta1. As a result, there is a large difference between these two cultures. Some aspects of the respective culture seem incredible to people belonging to the other culture. Many westerners even regard Chinese culture as the mysterious oriental culture.

\subsection{The differences between Chinese and western culture}

The differences between Chinese and western culture are numerous and complicated. To sum up, there are mainly the following aspects. First of all, cultural difference in convention. Cultural difference in convention is the difference in daily life and social intercourse result from the difference of custom and habit, such as the rules of using words to address, greet, express one's thanks, apologize, and phone, etc. Secondly, cultural difference in thought. Cultural difference in thought results from the way of thinking. As an instance, Chinese have the characteristic of thinking from top to bottom while the westerners the reverse. Thirdly, cultural difference in psychology. Cultural difference in psychology results from the mentality of a nation and consciousness of a society. Expression of the concept of value, ethics; implicit and roundabout ways to express one's feelings; Fourthly, cultural difference due to the difference of cultural development in history and accumulation of cultural legacy. Fifthly, cultural difference in posture. Culture can be represented through language. And without language, other signs of culture(such as gesture, fingering, facial expressions and clothing) can also represent it.

\section{Why should culture be included in English teaching?}

With the notion of over-emphasized adaptation to the need of the market, many English majors go to excess of learning some skills only and neglect the culture aptitude for language competence. In communication, they cannot find the right topic or proper expression; in reading, they feel it difficult to understand; in writing, they write English compositions in Chinese way's of thinking and many of their choices of words are Chinglish. Those lacking culture knowledge are usually those who are poor in English competence. So, we realize that it is necessary to enhance the teaching of culture in college English teaching.

\subsection{Interrelationship between language and culture}

Language is a social institution, both shaping and shaped by society at large or in particular the "cultural niches" (Eleanor Armour-Thomas\& Sharon-ann Gopaul-McNicol, 1 998). Thus, language should be understood as cultural 
practice, it cannot exist alone. Certainly, everyday language is tinged with cultural bits and pieces. By the very act of talking, people assume social and cultural roles, which are deeply entrenched in our thoughts, more often unnoticed and ignored though. In other words, the language people are speaking is culturally conditioned. Culture not only dictates who talks to whom, about what, and how the communication proceeds, it also helps to determine how people encode messages, the meanings they have for messages. So to speak, culture is the foundation of language.

Similarly, language is culture. When a person decides to learn English, for example, he or she is not merely absorbing the knowledge of the language, but everything to do with English and Britain and America. What he or she is taking in includes all the preconceptions about the English language, that it is beautiful, that it is world language, that it is spoken along the Shakespeare, and so on. Languages come with some cultural associations attached. By speaking the language, therefore, one automatically (to a greater or lesser extent) aligns oneself with the culture of the language. To speak a language well, one has to be able to think in that language, and thought is extremely powerful. A person' $\mathrm{s}$ mind is in a sense the centre of his identity, so if a person thinks in English way in order to speak English, one might say that he has, in a way, almost taken on an English identity(see for example Brown, 1994 and Littlewood, 1984). That is the power and the essence of a language. Language is culture.

Language is the soul of the country and people who speak it.

\subsection{Inseparability of culture teaching from language teaching}

The implications of the discussion above for the teaching of culture in language education are evident. Nowadays, researchers on EFL or ESL have attached much importance on culture teaching. Related studies have been carried out extensively on the vital place of culture in the foreign language classroom. Culture teaching is an essential part of language education. What is culture teaching exactly from a practical view?

In the field of foreign language teaching, one aspect that occasionally comes out as a topic of discussion is the relationship between linguistic knowledge of a foreign language, and knowledge of the culture of that target language. From the author's limited experience with foreign language education,it would appear to many language teachers that culture teaching means teaching courses of culture, it is supposed to lay out special courses such as American government, British history, literature, etc. The question of "culture" is often linked to the end of a language teaching plan. It seems as if it is always something of an addition if a teacher manages to find time to introduce a bit of the culture of the foreign language into the classroom- some music perhaps, a traditional wedding custom, Christmas, or stories from The Bible and Greek mythology, in the final minute of a class or in the final lesson of the course.

\subsection{Implications for teaching materials and contents}

The present study shows that the choice of Language and culture by Deng Yan--chang and Liu Run--qing as the textbook is proved to be all right, but it is not necessary for the teacher to be confined to its contents and arrangement. The teacher should read more books concerning culture in language teaching and try to get something useful to enrich the teaching content.

The results of the present study also strongly supports that the choice of the teaching materials and all the topics the author had taught must be included in the teaching plan. In teaching, what the teacher should spend more time are the following topics: idioms, proverbs and sayings; knowledge about culture; euphemisms and taboos; the similarity and difference in conversation; comparison between Chinese characters and English vocabulary because these are what the students are interested in most or what they think it is necessary to be explained more, or what they consider as the most difficult contents. Though ethnocentrism and body language are regarded as something unimportant to be explained less in class, they do goodness to cultivate the students' cultural awareness and enlarge their cultural knowledge and so it is necessary to mention them in class. Apart from these, the teacher should provide more sources for the students to widen their knowledge, such as Speaking Culturally by Johnson, Fern L, Idioms and Idiomaticity by Chitra Fernando, Comparison of Chinese and English Customs by DU Xue-zheng, etc.

\section{Conclusion}

All in all, Chinese culture, inclusive of the way of thinking and habitual expression, has a great influence upon students' English writing. As second language learners advance into certain language production stages, various influences brought about by the way of thinking in ones native language might increase correspondingly (WANG Dan — bin, 2002). A culture-related teaching and learning, involving the whole living style of a society and a language must be applied to the process of language learning and using. A language contains not only the historical and cultural background of that nation but also its viewpoints on the life, the living style and the way of thinking. In a society the language interacts with the culture. The ultimate aim of language teaching is to teach the students how to use a language. English writing is an integration of a student's English language competence and performance. It is true that under the good mastery of the English words and the styles, the culture has a great effect on the students' English writing. Therefore, in the teaching process of English writing it is necessary to help students to be conscious of the differences of Chinese and English culture. Only in this way, are Chinese students capable of reaching an understanding consensus of culture and 
language, and can they view things in English, thereby avoiding or overcoming the negative effects of native language to the full extent and producing pure English works.

\section{References}

Ajvg Suchun. (2007). Culture fusion and English language teaching. Sino-US English Teaching, Oct. Volume 4, No. 10 (Serial No. 46).

Bates. Daniel G, Fred Plog. (1990). Cultural anthropology. New York: Mc Graw-Hil1.

Dai, Xiaobing \& Cao Hng'. (2008). Influences of Chinese culture and mode of thinking on English writing. Sino-US English Teaching, Feb., Volume 5, No. 2 (Serial No. 50).

Deng, Yanchang \& Liu Runqing. (1989). Language and culture. Foreign Language Teaching and Research Press. (in Chinese).

Kramsch, Claire. (1999). Context and culture in language teaching. Shanghai Foreign Language Education Press.

Li, Guangmei. (2008). On the teaching content of Language and Culture. Sino-US English Teaching, May, Volume 5, No. 5(serial no.53).

Samovar, Larry A \& Richard E. Porter. (1985). Intercultural communication. Belmont, Calif: Wadsworth Pub. Co.

Wang, Danbin. (2002). Negative transfer of the Chinese way of thinking in English compositions. Journal of Shanghai Teachers University, (3), 118-124. 